\title{
Swirling devices intended for use in air ducts of dust emissions cleaning systems
}

\author{
I.V. Stefanenko \\ Chair "Building materials and special technologies" \\ Institute of Architecture and Construction of \\ Volgograd State Technical University \\ Volgograd, Russia
}

\author{
V.N. Azarov \\ Chair "Life Safety in Construction and Urban Management" \\ Institute of Architecture and Construction of \\ Volgograd State Technical University \\ Volgograd, Russia|
}

\author{
D.P. Borovkov \\ Chair "Life Safety in Construction and Urban Management" \\ Institute of Architecture and Construction of \\ Volgograd State Technical University \\ Volgograd, Russia \\ friggate@yandex.ru
}

I.V. Polyakov

EuroChem-VolgaKaliy

Volgograd, Russia

\begin{abstract}
The paper formulates the requirements for the flow swirlers intended for the installation in aspiration systems ducts, gives the description of the swirling devices aimed at enhancing the performance reliability of aspiration systems with the reduction of the amount of gas being cleaned, describes the aerodynamic characteristics of the suggested flow swirlers.
\end{abstract}

Key words-aspiration systems; flow swirling in air ducts; swirling devices; air ducts cleaning.

\section{INTRODUCTION}

In some cases in the process of aspiration systems operation, situations can emerge which cause the necessity to reduce the flow rate of exhaust gases from aspirated equipment. Such a situation appears, for example, when a number of equipment items served by the same aspiration system are switched off. Another reason dictating the necessity to reduce the aspiration volume exhausted by an aspiration system is a change of the operating practices of the aspirated equipment. The decrease in the process equipment load, as a rule, allows reducing the amount of exhaust air from this equipment into the aspiration system. Through this, we achieve a reduction of the power consumption by the draught equipment, a decrease in dust intake into the aspiration system and, hence, the saving of electrical energy and lessening of dust emissions into the atmosphere. In addition, the decrease in the aspiration volume at the reduced load on the drying plant (furnace, drum dryer, etc.) during the process of powder material drying typical for construction industry allows achieving a significant saving of thermal energy [1 - 4].

\section{EASE OF USE}

With the reduction of the gas volume going through the air ducts of an aspiration system, the velocity of the gas flow decreases. This results in the reduction of the transport capacity of the aspiration flow. Thus, when the aspiration volume of the gas exhausted from equipment by an aspiration system reduces significantly, dust deposits can start forming on inner surfaces of the air ducts $[1,2,4,5]$.
There are two main ways to solve the given problem: to organize the cleaning of air ducts in an aspiration system through blowing down with compressed air, and to prevent dust deposits formation through increased transport capacity of aspiration flow. The improvement of the conditions of dust particles transportation can be achieved by means of increasing the aspiration flow velocity through the reduction of aspiration air duct diameter. However, the reduction of the air duct diameter is non-rational supposing that the aspiration flow velocity is sufficient for stable transportation of dust particles during the aspiration system operation in the basic mode, and that, as a rule, the aspiration system operates in the reduced flow rate mode during considerably shorter time than in the basic mode. The reduction of air duct diameter will lead to a considerable increase in the aerodynamic resistance of the aspiration network and, as a consequence, to a considerable excessive consumption of electrical energy when the system operates in the basic mode. In addition, demounting and changing the aspiration network ducts located at a significant height is a labor-intensive and expensive operation that requires a long idle period of the aspirated equipment.

The most rational decision ensuring the aspiration system operation in the mode of reduced aspiration gas rate is the organization of flow swirling in the aspiration network ducts, which allows a significant improvement of the conditions of dust particles transportation without an increase in the gas flow rate in the duct $[1-4,6]$.

There are a lot of ways to swirl the flow going along a pipe. However, all of them can be divided into three main types: the use of a tangential inlet, the use of guide vanes, direct rotation of the flow (rotating pipe). The first two methods are most often used for practical purposes. In the first case, the air is put into a stationary pipe and imparted a spiral direction. The second approach that is generally widespread in heat-and-power engineering implies that the air is let in through a set of guide vanes. It should be noted that the use of the guide vane sets for two-phase flow transportation is difficult due to unavoidable sticking of disperse material particles to inner elements. 
The swirling of a flow through the method of pipe rotation allows getting a fully developed turbulent flow similar to the rotation of a solid body according to the motion character. However, this method has not gained a widespread use because of the complexity of the practical realization due to a number of design features among which the presence of rotating elements and the need for a mechanical drive should be mentioned. In addition, this method can provide only a relatively light degree of swirling.

Thus, of all the existing swirling devices, only chamber swirlers (the scroll-type and tangential ones) are suitable for practical use in aspiration systems. In terms of design, a tangential swirler is the simplest (fig. 1)
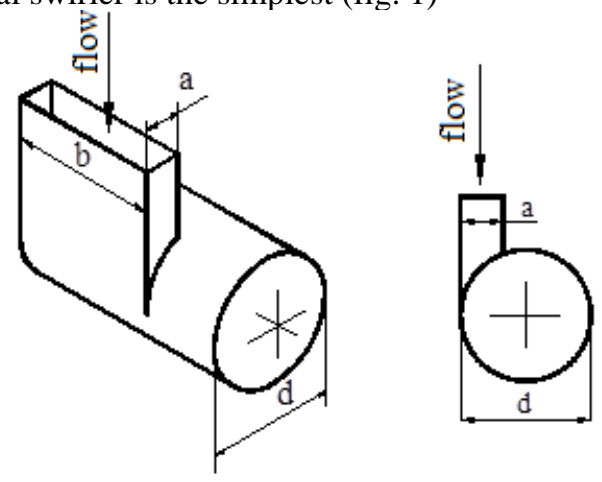

Fig. 1. Scheme of a tangential swirler with a single inlet $(\mathrm{d}-$ the diameter of the cylindrical part; $\mathrm{a}, \mathrm{b}-$ the linear dimensions of the cross-section of the tangential inlet)

For engineering purposes, when describing the intensity of flow swirling, it is most convenient to use the integral parameter $\Phi^{*}$ characterizing the ratio of the angular momentum $M$ to the axial translational momentum $\mathrm{K}$ at an arbitrary cross-section in scale of the linear size of channel $L$ :

$$
\Phi^{*}=M / K L
$$

$$
\text { where: } \begin{aligned}
M & =2 \pi \int_{0}^{R} \rho u \omega r^{2} d r \\
K & =2 \pi \int_{0}^{K} \rho \omega^{2} r d r
\end{aligned}
$$

For the main types of swirling devices, the expressions have been developed which allow determining the integral parameter of flow swirling obtainable at the outlet on the basis of the characteristic structural dimensions [5]. For tangential swirlers, the expression has the form:

$$
\Phi_{\text {outlet }}^{*}=\frac{\pi}{4} \cdot \frac{D(-a)}{a b} \cdot \cos \alpha
$$

The design of swirling devices intended for the organization of flow swirling in aspiration networks should meet the following requirements:
- ensuring the switching of the aspiration network from the axial mode to the swirling mode, and vice versa, without a break in the system operation;

- possibility of smooth regulation of the intensity of flow swirling generated by the swirling device.

For the organization of aspiration flow swirling in air ducts of an aspiration network when the system operates in the mode of reduced aspiration gas rate, an integrated tangential duct bend-swirler (an element connecting two air ducts at an angle) was suggested [7-12] the design of which is shown in fig. 2 . The distinguishing feature of the suggested device is a tangential duct branch (4) executed in the form of a bypass. When the aspiration system operates in the basic mode, the bypass duct branch (4) is hermetically closed with a shutter (5), the shutter of the axial duct branch (6) is open and the axial aspiration flow goes out of the outlet duct branch (2). In order to swirl the gas flow coming through the tangential duct bend-swirler, the shutter (5) of the tangential duct branch opens while the shutter (6) of the axial duct branch is transferred into the closed position.

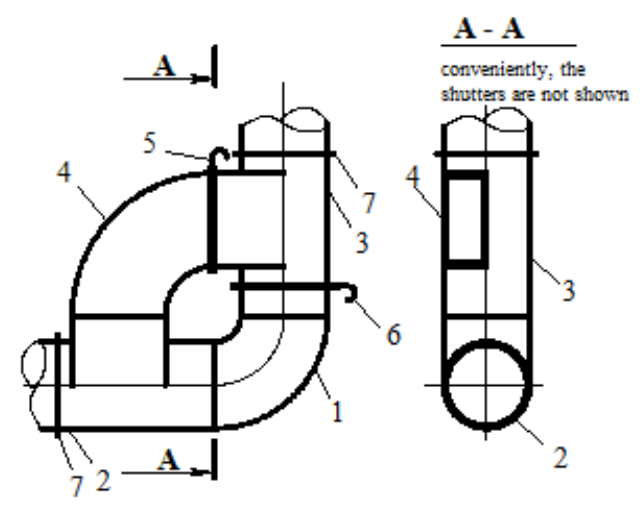

Fig. 2. Integrated tangential duct bend-swirler ( 1 - duct bend; 2 - outlet axial duct branch of the swirler; 3 - inlet axial duct branch of the swirler; 4 tangential duct branch; 5,6 - shutters; 7 - attachment flanges)

The local resistance coefficient obtained for the basic and axial modes of the swirler operation is considered as the response when the experimental studies aimed at determining the local resistance coefficient of the integrated tangential duct bend-swirler are carried out. The following values were selected as the determining factors: $\Phi_{\text {geom }}^{*}-$ the form parameter of the swirler, and $\bar{a}$ - the design parameter characterizing the ratio of the width of the tangential inlet cross-section to the diameter of the cylindrical part. As a result of the approximation of the experimental data by a seconddegree polynomial, the following regression equations were obtained:

Swirling mode:

$$
\begin{aligned}
& \xi_{\text {swirler }}=2,583+0,370 \cdot \Phi_{\text {geom }}^{*}-2,339 \cdot \bar{a}- \\
& 3,520 \cdot \Phi_{\text {geom }}^{*} \cdot \bar{a}+1,071 \cdot \Phi_{\text {geom }}^{* 2}+5,481 \cdot \bar{a}
\end{aligned}
$$

Axial mode: 


$$
\begin{aligned}
& \xi_{\text {swirler }}=0,660+0,006 \cdot \Phi_{\text {geom }}^{*}+1,031 \cdot \bar{a}- \\
& 0,019 \cdot \Phi_{\mathrm{geom}}^{*} \cdot \bar{a}-0,023 \cdot \Phi_{\mathrm{geom}}^{* 2}-0,807 \cdot \bar{a}^{2}
\end{aligned}
$$

In order to blow down the aspiration network ducts under depression with a swirled air flow, the authors suggest a tangential-type swirling device $[10,11,13]$ for the purpose of dust deposits removal, fig. 3. The main specific feature of the suggested swirler is the presence of a shutter to block the axial duct branch and of two inclined tangential inlets with hermetic-tight cover caps.

When the aspiration system operates in the basic mode, the tangential duct branches (1) are hermetically closed with the cover caps (2). At the same time, a non-swirled aspiration flow goes along the axial duct branch (4). When the aspiration system is blown down, the cover caps (2) are removed from the tangential duct branches (1), and the shutter (5) is transferred into the closed position.

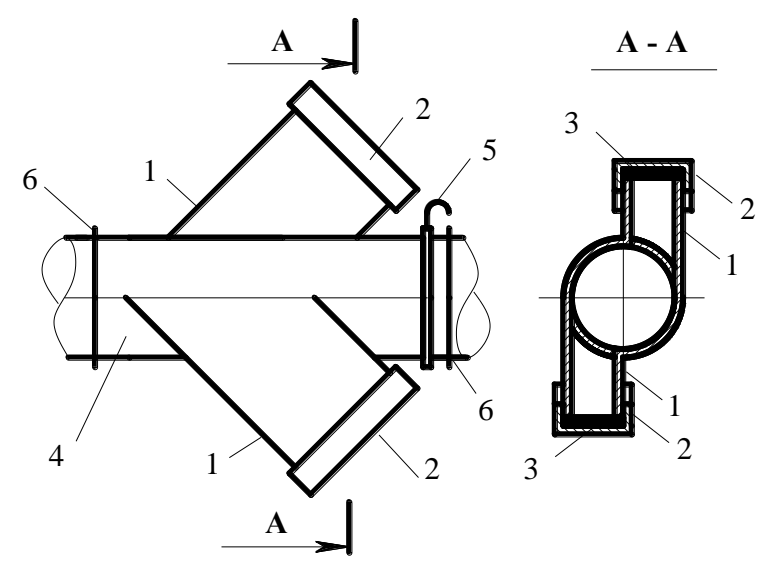

Fig. 3. Device for air ducts cleaning with a swirled flow (1 - tangential duct branch; 2 - cover cap; 3 - gasket; 4 - axial duct branch; 5 - shutter; 6 attachment flange)

Opening the tangential duct branches leads to the air leakin from the environment into the aspiration duct. At the same time, the aspiration flow rate at the section located ahead of the swirler reduces. And an increased-rate flow goes out of the swirler, being partly swirled with tangential streams and imparted a significantly larger transport capacity in comparison with the non-swirled aspiration flow at the same section in the basic mode of aspiration system operation. In the case if it is necessary to increase the intensity of air flow swirling in the duct, the shutter (5) is closed. After the shutter (5) is closed, the movement of the flow at the section located ahead of the swirler stops, and a fully swirled flow goes out of the swirler; the transport capacity of the given swirled flow considerably exceeds the transport capacity of a partly swirled flow due to larger swirling intensity. In order to return the system to the operation mode, the shutter (5) is opened, and after a short time period the tangential duct branches (1) are closed hermetically with the cover caps (2).

Three-way connectors are suggested to be used as the devices intended for the swirled movement generation in air ducts of branched aspiration systems. This solution is the most advantageous one from the point of view of energy, since it allows using the change of the flow movement direction for the purpose of the flow swirling. In order to organize flow swirling in air ducts, the authors suggest several designs of three-way connectors-swirlers, the main specific feature distinguishing them from the existing ones is the use of an inclined slide gate as a swirl-generating element $[10,11,13$, 14 ] (fig. 4). a)

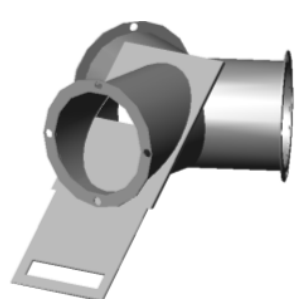

b)

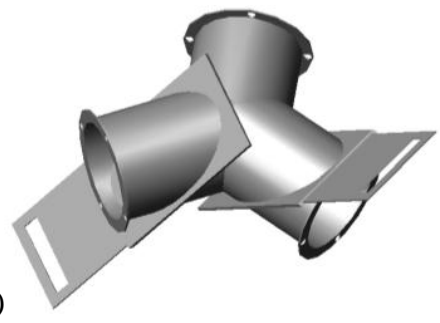

c)

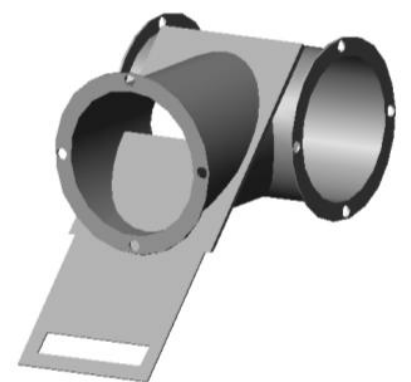

Fig 4. Designs of swirling devices with an inclined slide gate (a - three-way connector-swirler for flow splitting; $b$ - three-way connector-swirler for flows merging; c - three-way connector-twister (for light swirling) for flows merging)
The tangential channel is formed by the inner surface of the air duct and the inclined slide gate. The slide gate movement along the guide frames allows for a smooth regulation of the area of the inlet cross-section and, hence, the parameter of the flow swirling. This significantly facilitates the regulation of the aerodynamic mode of branched aspiration systems.

In the process of the experimental studies aimed at determining the local resistance coefficients of three-way connectors-twisters, the following values were selected as the determining factors: $\alpha$ - the angle between the axes of the connected air ducts of three-way connector-twister; $d_{\text {branch }} / d_{\text {trunk }}$ - the ratio of the branch diameter to the trunk diameter; $L_{\text {branch }} / L_{\text {trunk }}$ - the ratio of the flow rate in a branch to the flow rate in the trunk; $\Phi^{*}-$ the form parameter of the swirler (the scheme of the sizes is given in fig. 5). 


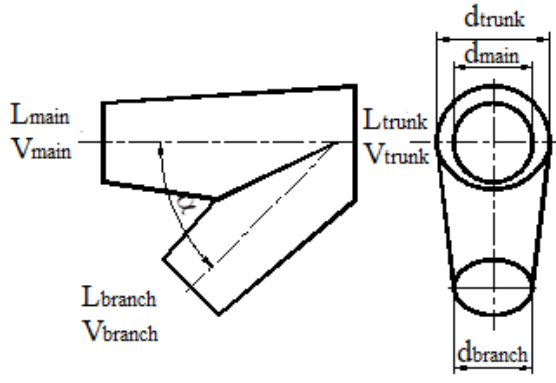

Fig. 5. Three-way connector-twister for light swirling with adjustable swirling intensity (Note: conventionally, the inclined slide gates are not shown)

As a result of the experimental data processing for the swirlers with various angles of branch connection $(\alpha)$, the authors obtained the regression equations of the form

$$
\zeta_{\text {main }}=f \bigotimes_{\text {branch }} / d_{\text {trunk }}, \Phi^{*}, L_{\text {branch }} / L_{\text {trunk }}
$$

and $\zeta_{\text {branch }}=f{\boldsymbol{\psi _ { \text { branch } }}} / d_{\text {trunk }}, \Phi^{*}, L_{\text {branch }} / L_{\text {trunk }}$

The results of the experimental studies were approximated by the third-degree polynomial of the form:

$$
\begin{aligned}
& \zeta=b_{0}+b_{1} X_{1}^{3}+b_{2} X_{2}^{3}+b_{3} X_{3}^{3}+b_{4} X_{1}^{2}+b_{5} X_{2}^{2}+b_{6} X_{3}^{2}+ \\
& b_{7} X_{1}+b_{8} X_{2}+b_{9} X_{3}+b_{10} X_{1} X_{2} X_{3}
\end{aligned}
$$

where: $X_{1}-$ the ratio of the branch diameter to the trunk diameter; $X_{2}-$ the integral parameter of flow swirling $\Phi^{*}$ generated by a three-way connector-twister; $X_{3}$ - the ratio of the air rate in a branch to the air rate in the trunk; $L_{\text {branch }} / L_{\text {trunk }} ; b_{0}, b_{1} \ldots b_{10}-$ coefficients of the regression equation. 1 .

The values of the regression coefficients are given in table

It is obvious that in the non-swirled flow mode (when the shutter does not block the cross-section), the suggested threeway connectors do not practically differ from the standard ones and their installation in the functioning aspiration system does not lead to any increase in the aerodynamic resistance. In the case if it is necessary to change the gas (dust-gas mixture) rate going along a branch, the suggested three-way connector acts as a swirler (twister) and, simultaneously, as a flow rate regulator.

The simplicity of the suggested structures manufacturing is not an insignificant advantage: the suggested three-way connectors can be easily produced from the existing standard

\begin{tabular}{|c|c|c|c|c|c|c|c|}
\hline \multicolumn{2}{|c|}{$\begin{array}{l}\text { Type of } \\
\text { local } \\
\text { resistance }\end{array}$} & $\begin{array}{l}\alpha=30 \\
o \\
\text { branc } \\
h\end{array}$ & $\begin{array}{l}\alpha=30 \\
; \\
\text { main }\end{array}$ & $\begin{array}{l}\alpha=60 \\
o \\
\text { branc } \\
h\end{array}$ & $\begin{array}{l}\alpha=60 \\
\circ \\
\text { main }\end{array}$ & $\begin{array}{l}\alpha=90 \\
\circ, \\
\text { branc } \\
h\end{array}$ & $\begin{array}{l}\alpha=90 \\
\circ, \\
\text { main }\end{array}$ \\
\hline \multirow{11}{*}{$\begin{array}{c}\text { Coeff } \\
\text { icient } \\
\text { s of } \\
\text { regre } \\
\text { ssion } \\
\text { equat } \\
\text { ions }\end{array}$} & $\mathrm{b}_{0}$ & 2,23 & 0,51 & 7,30 & 0,57 & 4,76 & 0,57 \\
\hline & $b_{1}$ & 1,42 & $-0,38$ & 2,17 & $-0,43$ & 1,56 & $-0,50$ \\
\hline & $\mathrm{b}_{2}$ & 1,10 & $-0,07$ & 1,55 & $-0,04$ & 1,99 & $-0,02$ \\
\hline & $b_{3}$ & 0,17 & $-0,05$ & $-0,32$ & $-0,05$ & $-0,02$ & $-0,05$ \\
\hline & $\mathrm{b}_{4}$ & $-0,40$ & 0,38 & $-1,23$ & 0,45 & $-0,65$ & 0,51 \\
\hline & $b_{5}$ & $-1,56$ & $-0,40$ & $-1,67$ & $-0,48$ & $-1,80$ & $-0,51$ \\
\hline & $b_{6}$ & $-0,29$ & 0,28 & 3,16 & 0,28 & 1,23 & 0,30 \\
\hline & $b_{7}$ & $-0,91$ & 0,87 & $-1,34$ & 1,01 & $-0,68$ & 1,14 \\
\hline & $b_{8}$ & $-3,76$ & $-0,57$ & $-3,59$ & $-0,74$ & $-4,77$ & $-0,81$ \\
\hline & $b_{9}$ & $-1,70$ & $-0,74$ & $-8,92$ & $-0,77$ & $-5,29$ & $-0,82$ \\
\hline & $b_{1}$ & 4,61 & 0,25 & 3,83 & 0,31 & 5,08 & 0,32 \\
\hline
\end{tabular}
ones.
TABLE I. Coefficients of regression equations

\section{CONCLUSIONS}

1. The use of the devices allowing for a swirled and axial movement of dust-gas flow along air ducts makes it possible to achieve a significant energy saving during the operation of the aspiration systems with a changeable rate of the gas to be cleaned;

2. Of all the existing swirling devices, tangential swirlers are the most suitable for practical use in aspiration systems.

3. The designs of the swirling devices.lintended for the organization of flow swirling in aspiration networks should ensure the switching of the aspiration network from the axial mode to the swirled flow mode and vice versa without a system shutdown as well as allow for smooth regulation of the flow swirling intensity generated by the swirling device.

4. The described designs of tangential-type swirling devices intended for the organization of flow swirling in air ducts of aspiration systems of various purposes and packaging meet the above mentioned requirements to the full extent;

5. The experimental dependences which allow determining the aerodynamic resistance of the suggested swirling devices both in the swirled and axial flow modes were obtained.

Nomenclature:

$M$ - angular momentum of a flow; $K$ - axial translational momentum of a flow; $L$ - channel linear scale; $D$ - diameter of the cylindrical part of a swirler; $a, b$ - linear dimensions of cross-section of the swirler's tangential inlet referred to the diameter of the cylindrical chamber; $\alpha-$ angle of the inclination of tangential duct branch axis to the air duct axis; $p$ - pressure; $u$ - axial component of gas velocity in the channel cross-section; $\omega$ - tangential component of gas velocity in the channel cross-section; $r$ - duct cross-section radius, $\rho-$ density; $\Phi^{*}-$ integral parameter of flow swirling; $\Phi_{\text {geom }}^{*}$ integral parameter of flow swirling generated by the swirler. 


\section{References}

[1] V.N. Azarov, D.P. Borovkov, A.M. Redhwan, Application of swirling flows in aspiration systems. International Review of Mechanical Engineering, vol. 4, pp. 750-753, 2014.

[2] V.N. Azarov, D.P. Borovkov, On the use of flow swirling in aspiration systems at construction industry enterprises, Proceedings of Construction Sciences Department of RAACS, vol. 16, pp. 12-17, 2012.

[3] V.N. Azarov, D.P. Borovkov, The use of flow swirling in aspiration systems at construction industry enterprises, Construction Materials, vol. 5, pp. 65-67, 2012.

[4] V.N. Azarov, D.P. Borovkov, D.A. Skorikov, On the use of swirled flows in aspiration systems ducts at construction industry enterprises, Scientific works SWorld journal, vol. 3. pp. 32-38, 2011.

[5] D.P. Borovkov, K.O. Chichirov, Aerodynamic analysis of aspiration systems for flow swirling organization in air ducts, Regional Architecture and Construction, vol. 3, pp. 145-148, 2012.

[6] V.F. Zheltobryukhov, D.P. Borovkov, Analysis of reasons of aspiration systems clogging in construction industry, In the collected works: Issues of Protection of Industrial and Natural Environment, Proceedings of Scientific-and-Technical Conference, pp. 179-180, 2001.

[7] V.N. Azarov, D.P. Borovkov, S.V. Filippova, On the transportation of dust particles with swirled flows in air ducts of aspiration systems and dedusting ventilation, Proceedings of the South-West State University, vol. 3-1 (42), pp. 113-119, 2012.

[8] D.P. Borovkov, Increasing the resistance of aspiration systems to clogging by means of aspiration flow swirling in air ducts. In the collected works: Issues of Protection of Industrial and Natural Environment, Proceedings of Scientific-and-Technical Conference, 2001. p.p. 182-183.

[9] D.P. Borovkov, D.A. Skorikov, On the use of flow swirling in aspiration system ducts at construction industry enterprises, InternetVestnik VolgGASU. 2012. vol. 2 (22). p.p. 13.

[10] D.P. Borovkov, D.A. Skorikov, Devices for flow swirling generation in air ducts of aspiration systems, Internet-Vestnik VolgGASU, vol. 1 (25), pp. 3-4, 2013.

[11] D.P. Borovkov, S.A. Stepanov, V.G. Kamburg, K.O. Chichirov, Reconstruction of the aspiration system of drying equipment at construction industry enterprises by means of flow swirling in air ducts, Regional Architecture and Construction, vol. 1, pp. 123-128, 2012.

[12] V.N. Azarov, V.F. Zheltobryukhov, D.P. Borovkov, Device for the cleaning of aspiration system ducts under excess pressure, utility model patent RUS 35325 05.06.2003.

[13] V.N. Azarov, D.P. Borovkov, V.N. Martyanov, D.V. Azarov, Device for dust removal from air ducts, utility model patent RUS 33755 05.06.2003.

[14] V.N. Azarov, A.O. Yudochkina, D.P. Borovkov,Fluid flow swirler, utility model patent RUS 50284 18.08.2005. 